Revue bibliographique pour le domaine irano-aryen

\title{
Stoyanka Kenderova, Catalogue des manuscrits orientaux du Département d'Etudes turques de l'Université de Strasbourg
}

Nourane Ben Azzouna

\section{(2) OpenEdition}

Journals

Édition électronique

URL : http://journals.openedition.org/abstractairanica/39920

DOI : 10.4000/abstractairanica.39920

ISSN : 1961-960X

Éditeur :

CNRS (UMR 7528 Mondes iraniens et indiens), Éditions de l'IFRI

Édition imprimée

Date de publication : 1 décembre 2013

ISSN : 0240-8910

Référence électronique

Nourane Ben Azzouna, « Stoyanka Kenderova, Catalogue des manuscrits orientaux du Département d'Etudes turques de I'Université de Strasbourg », Abstracta Iranica [En ligne], Volume 32-33 | 2013, document 1, mis en ligne le 01 juillet 2016, consulté le 26 septembre 2020. URL : http:// journals.openedition.org/abstractairanica/39920 ; DOI : https://doi.org/10.4000/abstractairanica 39920

Ce document a été généré automatiquement le 26 septembre 2020.

Tous droits réservés 


\title{
Stoyanka Kenderova, Catalogue des manuscrits orientaux du Département d'Etudes turques de l'Université de Strasbourg
}

\author{
Nourane Ben Azzouna
}

\section{RÉFÉRENCE}

Catalogue des manuscrits orientaux du Département d'Etudes turques de l'Université de Strasbourg. Rome, Instituto per l'Oriente «C. A. Nallino » - CNRS « Mondes Iranien et Indien », 2009, 270 p. (Series Catalogorum n. 3)

1 Ce catalogue est le troisième volume de la "Series Catalogorum " co-publiée par l'Instituto per l'Oriente «C.A. Nallino» de Rome et l'UMR7528 «Mondes iranien et indien » de Paris. Après le catalogue des manuscrits orientaux du Musée régional de Qarshi (2004) et celui du Musée régional de Nukus (2007), tous deux en Ouzbékistan, ce catalogue présente une autre collection méconnue: celle du Département d'études turques de l'Université de Strasbourg.

2 Il s'agit d'une petite collection de soixante-trois codex et neuf fragments (de un à six feuillets) en arabe, turc et persan. L'un de ces manuscrits, un Šāhnāme datable du XVI ${ }^{\mathrm{e}}$ s. (MS P6), faisait partie de la collection du grand maitre des études sémitiques et islamiques Theodor Nöldeke (1836-1930) qui a enseigné à l'Université de Strasbourg de 1872 à 1906. Ce manuscrit a été offert par l'Institut de linguistique au Département d'études turques de l'Université de Strasbourg. Les autres manuscrits ont probablement été réunis par le professeur René Giraud qui, après avoir enseigné dans différentes institutions à Ankara, a dirigé la chaire de turcologie de Strasbourg de 1964 à 1968. Depuis son entrée au Département, le fonds est resté inexploité jusqu'au travail 
effectué par S. Kenderova qui a commencé par reconstituer les volumes dispersés, avant de procéder à leur classement, cotation et catalogage.

3 Le fonds comprend donc soixante-douze manuscrits: quarante-huit arabes ou majoritairement arabes, dix-huit turcs ou majoritairement turcs (seize ottomans et deux čagatāy) et six persans. Plusieurs de ces manuscrits sont composites, avec deux ou plusieurs textes, parfois plusieurs langues, ce qui fait un total de cent vingt-quatre textes. Le catalogue suit précisément le classement des textes, ce qui fait que plusieurs manuscrits sont présentés dans plusieurs notices. Par exemple, MS A3 est présenté dans les notices $n^{\circ} 121,86$ et 9 . Ce choix est parfois déroutant, d'autant plus lorsque, comme dans MS A3, les divers textes sont eux-mêmes composites et que certains sont copiés sur le même type de papier et par le même copiste. La vision que l'on a de l'intégralité du manuscrit et de son histoire est ainsi malheureusement fragmentée. Certains recueils sont en revanche présentés dans des notices séparées alors qu'ils pourraient rejoindre d'autres sections du catalogue, comme certaines sélections coraniques $\left(n^{\circ} 120,122\right)$ la première section sur les Corans.

Le catalogue suit donc le classement, thématique, des textes, quelle que soit leur langue. Le fonds est typiquement composé d'une majorité de textes religieux en arabe (Corans, sciences coraniques, Hadiț, théologie, droit, en particulier hanafite...), puis philologiques (belles lettres, grammaire, lexicographie, rhétorique...), et enfin philosophiques et logiques (notamment plusieurs commentaires de İsāgūjī de Atīir alDīn al-Abharī (m. 663/1264)). Il ne contient en revanche que très peu d'ouvrages à caractère scientifique (médecine, pharmacologie, astronomie). Les ouvrages de belles lettres, comme les ouvrages scientifiques, sont uniquement en persan et en turc. La présence de plusieurs textes à caractère officiel: un code de Soliman $\mathrm{I}^{\text {er }}$ (926-974/1520-66) et plusieurs manuels de composition de documents juridiques et épistolographiques turcs mérite aussi d'être notée. Le fonds comprend aussi plusieurs dictionnaires bilingues.

5 Suivant le standard établi pour "Series Catalogorum", les notices présentent des informations détaillées aussi bien sur le texte et l'auteur que sur la copie, en particulier le colophon et l'aspect physique du manuscrit : écriture, réglure, papier - avec une description précise des filigranes - cahiers, état de conservation, reliure, et une reproduction est associée à chaque notice. Quelques manuscrits, en particulier du XVI s., se distinguent par une calligraphie Nasta'līq de qualité et des décors enluminés. Plusieurs sont reproduits en couleur. Enfin, le catalogue se distingue par un travail méticuleux sur les gloses et les notes dont certaines sont intégrées dans les index. Ceux-ci sont très détaillés, avec notamment un index pour les possesseurs et les donateurs, très utile pour l'histoire des manuscrits. 


\section{AUTEURS}

\section{NOURANE BEN AZZOUNA}

Agence France Muséums-Louvre, Abu Dhabi 